\title{
História ambiental do pré-sal: meio ambiente e mudanças sociais em São Paulo, Brasil (2007-2016)
}

\author{
Environmental history of pre-salt: environment and social change in São Paulo, \\ Brazil (2007-2016)
}

\author{
Paulo Henrique Martinez ${ }^{*}$, Roger Domenech Colacios ${ }^{*}$ \\ [martinezph@uol.com.br] [rdcolacios@gmail.com]
}

Recibido: 29 de julho de 2016

Aprovado: 12 de dezembro de 2016

DOI: $10.5935 / 2237-2717.20160015$

Citação sugerida: Martinez, Paulo H., e Roger Colacios. "História ambiental do pré-sal: meio ambiente e mudanças sociais em São Paulo, Brasil (2007-2016)." HALAC VI, no. 2 (Diciembre 2016): 263-277.

\begin{abstract}
RESUMO
Este artigo tem por objetivo 0 estudo do comprometimento da sustentabilidade ambiental e das mudanças sociais causadas pela exploração do Pré-sal no litoral de São Paulo, Brasil. Desde 2007, ano do anúncio pelo Governo Federal da existência de reservas petrolíferas na camada de Pré-sal, até 2016, houve a instalação, a reforma e a ampliação da infraestrutura da indústria petrolífera na região. As cidades da zona costeira paulista passaram a conviver com índices crescentes de vazamento de petróleo, acidentes de trabalho, ocupação irregular do solo, inchaço demográfico, epidemias, deterioração de seus equipamentos sociais e conflitos com as comunidades caiçaras e indígenas. 0 processo de consolidação da atividade petrolífera comprometeu os sistemas hídricos, a biodiversidade e aumentou os riscos das mudanças climáticas. Esses elementos, quando analisados em sua unidade, mostram que a presença do Pré-sal teve vantagens e adversidades, ampliação das oportunidades econômicas e dos prejuízos ambientais e sociais.
\end{abstract}

\section{Palavras chaves}

História Ambiental, Pré-sal, Meio Ambiente, Mudanças Sociais, São Paulo (estado brasileiro).

\section{ABSTRACt}

This article aims to study the environmental sustainability commitment and social changes caused by the exploitation of Presalt in the São Paulo coast. Since 2007, year of the announcement by the Federal Government of the existence of oil reserves in the pre-salt layer, until 2016, there was the installation, renovation and expansion of the oil industry infrastructure in the region. The cities of São Paulo coastal zone started to live with increasing levels of oil spills, industrial accidents, irregular land use, demographic swelling, epidemics, deterioration of its social facilities and conflicts with the native population and indigenous communities. The consolidation of the oil activity undertaken water systems, biodiversity and increased the risks of climate change. These elements when analyzed in their unit show that the Pre-salt presence had advantages and adversities, expansion of economic opportunities and environmental and social damage.

\section{KEYWORDS}

Environmental History, Pre-salt, Environment, Social Changes, São Paulo (Brazilian state).

Redução das desigualdades sociais, melhor distribuição de renda, acesso à cultura, educação, esporte, saúde, fomento à pesquisa, geração de empregos e sustentabilidade ambiental. Todos são objetivos presentes nos discursos governamentais relacionados ao

\footnotetext{
* Professor da Universidade Estadual Paulista Júlio de Mesquita Filho (UNESP), campus Assis, Brasil. Coordenador do Laboratório de História e Meio Ambiente (LABHIMA). Livre docente.

${ }^{* *}$ Pós-doutorando, Laboratório de História e Meio Ambiente (LABHIMA), Universidade Estadual Paulista Júlio de Mesquita Filho (UNESP), campus Assiss, Brasil.
} 
Pré-sal. Anunciadàs em 2007 e estimadas em bilhões de barris de petróleo as jazidas em águas profundas, abaixo de dois mil metros de profundidade e distantes 200 quilômetros do litoral brasileiro, serviram aos projetos econômicos e sociais dos governos Lula e Dilma Rousseff. Os lucros do Pré-sal foram a principal base de investimentos em infraestrutura, de estímulo à indústria e ao consumo interno no país. A composição de um Fundo Social e a distribuição dos royalties para todos os estados e municípios deveriam servir para a melhoria geral das condições de vida da população brasileira. O Governo Federal previa o início de um ciclo de desenvolvimento econômico e social a partir da exploração do Pré-sal.

Os investimentos diretos estiveram voltados para atender algumas das principais carências da sociedade brasileira. Já os investimentos indiretos, com a execução de projetos infraestruturais e uma política industrial vigorosa deveriam resultar em benefícios para a população. Megaprojetos, como a construção ou ampliação de portos, construção de oleodutos, estaleiros, refinarias e estradas, foram iniciados. Um imenso canteiro de obras que necessitaria de milhares de trabalhadores e consequentemente gerando postos de trabalho em diversas regiões do país. Um ciclo no qual a existência de empregos por sua vez seria traduzida em desenvolvimento econômico e social, com a aumento da circulação monetária no comércio e o consequente estímulo à indústria nacional. Os investimentos para a dinamização da extração petrolífera foram estimados em torno de 380 bilhões de reais no ano de 2012. Voltados quase que exclusivamente para: "estaleiros especializados em construção de plataformas, sondas, embarcações nos estados do Rio de Janeiro, Rio Grande do Sul, Pernambuco, Alagoas, Bahia e Espirito Santo [...]". ${ }^{1}$ No total o montante destinado às obras visando o beneficiamento e o escoamento da produção do Pré-sal atingiria a marca próxima de 1,7 trilhão de dólares até $2040{ }^{2}$

Neste cenário de investimentos maciços, as áreas litorâneas receberam grande parte da infraestrutura e o maior impacto ambiental e social quando comparadas com o restante do país. A proximidade das cidades costeiras com as plataformas petrolíferas e as estruturas já construídas ou em construção, para facilitar o transporte e a transformação do petróleo em seus derivados, as colocam na linha de frente das obras para a exploração do Pré-sal. Em destaque as cidades da região litorânea de São Paulo, principalmente na Baixada Santista. Os municípios de Peruíbe, Mongaguá, Santos, Cubatão, São Sebastião, Praia Grande, São Vicente, Bertioga e Guarujá estão no centro desses investimentos para as atividades envolvendo o Pré-sal.

A precariedade das estruturas da indústria petrolífera nestas cidades do litoral paulista drenou a concentração dos investimentos infraestruturais em toda a região. As obras têm o objetivo de criar e reformar o complexo viário, industrial e de serviços e estão voltadas para atender a demanda imediata e futura das atividades petrolíferas. A iniciativa do Governo Federal pretendia assegurar que a dinâmica de extração do petróleo fosse realizada sem empecilhos, viabilizando o projeto político econômico neodesenvolvimentista. ${ }^{3}$

Os canteiros de obras no litoral paulista significam também a alteração da paisagem urbana da região. A modificação das cidades litorâneas de São Paulo devido ao Pré-sal é

\footnotetext{
${ }^{1}$ Luiz A. Cintra, "A Fronteira É O Mar," Carta Capital, 11 jul, 2012.

${ }^{2}$ Cf. Daniele Nogueira; Bruno Rosa, "Investimentos no Pré-sal para os Próximos 30 anos Movimentarão US\$ 1,7 trilhão," 0 Globo, 19 out., 2013.

${ }^{3}$ Cf. Leonardo R. Teixeira et al, "Megaprojetos no Litoral Norte de São Paulo, Brasil: uma análise integrada", in Anais $2^{a}$ Conferência da REDE de língua portuguesa de avaliação de Impactos e $1^{\circ}$ Congresso Brasileiro de avaliação de impacto. Associação brasileira de avaliação de impacto, 2012, s/p; Wellington T. Lisboa; Taise F. Luz, "Mar d'ouro? Da expansão do porto à centralidade do Pré-sal: estratégias comunicativas no mercado emergente da Baixada Santista", in Comunicologia - Revista Comunicação e Epistemologia da Univērsidade Católica de Brasília, 5, (2012), 46-70; Vanessa M. Massara et. al, "Desenvolvimento regional ña região metropolitana de Santos e o Pré-sal", in G\&DR, 10, (2014) 257-280.
} 
um caminho irreversível. O comprometimento dos sistemas ambientais e sociais pode ser considerado como a marca indelével da indústria petrolífera. É reconhecida sua capacidade em alterar a composição da população e a ecologia nas regiões onde desenvolve sua atividade exploratória. ${ }^{4} \mathrm{O}$ litoral paulista, pelas obras em andamento, mostra que não será exceção no histórico da exploração de petróleo. As modificações já estão ocorrendo desde 2007 e a extração de petróleo ainda está longe de atingir seu potencial máximo, previsto para as próximas décadas.

A alteração social e ambiental nessas cidades tem como ponto central as rendas do Pré-sal. Através dos royalties e dos financiamentos federais houve o aumento no fluxo monetário, levando a circulação de moeda em todos os setores da economia regional. Tais fatores são uma fonte de atrativos variados. A economia aquecida as cidades do litoral representam oportunidade de emprego e investimento. Estes locais tornam-se destino de imigrantes e investidores, um atraindo o outro. As consequências, quando estas situações não são permeadas com políticas públicas eficientes, acabam criando uma realidade perversa sobre estes municípios. Inchaço demográfico e a consequente sobrecarga da infraestrutura urbana (postos de saúde, hospitais, creches, escolas, instituições culturais). Intensificação dos conflitos sociais por moradia, pelo estilo de vida, pela cultura sobretudo das comunidades caiçaras e povos indígenas. Limites ecológicos alcançados, com a expansão urbana sobre as áreas protegidas ou de frágil equilíbrio da biodiversidade, aumento da poluição atmosférica, aquática, sonora e a contribuição para as mudanças climáticas, devido ao aumento da população e da falta de estrutura para conter as emissões de poluentes.

O Pré-sal, em todas as etapas de sua atividade exploratória promove alteração significativa das áreas de proximidade direta com os campos onde estão localizados. Meio ambiente e a sociedade sofrem modificações. O enquadramento dessas alterações torna-se uma questão necessária na compreensão do lugar que o Pré-sal tem na sociedade brasileira. O Pré-sal ao ser avaliado em relação aos ganhos econômicos e políticos tem destaque, quando observado sob a perspectiva ambiental e social os prejuízos que causa precisam ser contabilizados.

Utilizando como fontes artigos de jornais, revistas e dados estatísticos este artigo estuda a relação entre a exploração do Pré-sal, o comprometimento ambiental e as mudanças sociais em São Paulo entre 2007 e 2016. O texto está divido em duas partes. Na primeira é discutida a situação ambiental do litoral paulista, com ênfase nas principais alterações provocadas pelas atividades da extração do Pré-sal junto aos ecossistemas, a biodiversidade e as mudanças climáticas. A parte final trata das mudanças sociais nas cidades costeiras de São Paulo originando uma nova paisagem urbana promovida pelos investimentos e os royalties do Pré-sal.

\section{Pré-sal e meio ambiente no litoral paulista}

As zonas costeiras são áreas de grande densidade populacional. Estudos da ONU apontam que em 1994 ao redor de 37\% da população mundial habitava em um raio de 60 km das áreas litorâneas. Recentemente esta porcentagem foi elevada para 50\%. No Brasil, apesar da colonização ter se concentrado na zona costeira, esse número cai para 20\% da população. ${ }^{5}$ A presença humana acentuada neste ambiente causa significativo

\footnotetext{
${ }^{4}$ Cf. Mirna Santiago, The ecology of oil: environment, labor, and the Mexican Revolution, 1900-1938, (New York: Cambridge University Press, 2006).

${ }^{5}$ Cf. Claudio Freitas Neves; Dieter Muehe, "Vulnerabilidade, impactos e adaptação a mudanças do clima: a zona costeira", in Parcerias Estratégicas, 27, (2008), 217-295.
} 
comprometimento aos sistemas naturais. O excessivo consumo, a industrialização e o turismo são algumas causas de degradação, embora não sejam as principais. Enquanto áreas de transição entre continente e oceanos, as zonas costeiras recebem o afluxo de poluentes do interior. A utilização dos oceanos como depósito de dejetos (esgoto, lixo, resíduos químicos, produtos tóxicos) figura como importante causa de poluição das áreas litorâneas. ${ }^{6}$

A contaminação das áreas litorâneas tem diversas fontes. O uso de agrotóxicos e fertilizantes, a utilização de mercúrio, os vazamentos de petróleo, o despejo de águas residuais e os poluentes atmosféricos figuram entre os focos de poluição ambiental que encontram nestas áreas um espaço de acumulação. A dragagem de portos, construção de vertedouros, estradas, casas e apartamentos, a derrubada de florestas, a mineração de areia nas praias, o soterramento de mangues, são outras atividades que tem provocado a alteração física do habitat litorâneo em todo o mundo. Os poluentes e as atividades predatórias têm apresentado danos ambientais nos últimos anos. A diminuição da oxigenação das águas oceânicas levou a eutrofização e o aumento das atividades de fitoplânctons. Fenômenos como a maré vermelha têm sido mais constantes em algumas partes do planeta, afetando a biodiversidade marinha e litorânea e a saúde pública. Cientistas e médicos notaram nestas regiões a intensificação de casos de doenças, surtos epidêmicos e infecções. Atividades simples, corriqueiras ou necessárias, como banhar-se no mar, consumir alimentos e água são os principais meios de contaminação dos habitantes e turistas. ${ }^{7}$

Não obstante essas fontes diretas e indiretas, as atividades econômicas típicas das regiões costeiras exercem sua parcela de pressão sobre o meio ambiente. Cientistas apontam que uma boa parte das espécies de peixes e plantas marinhas ocupam as faixas oceânicas próximas ao litoral. ${ }^{8}$ Esta característica faz com que a aquicultura e a pesca intensiva, extração em escala industrial de peixes e frutos do mar, contribuam com a diminuição da biodiversidade marinha. Em meados da década de 1970 a pescaria retirava dos oceanos uma quantidade de cem milhões de toneladas de peixes por ano. Segundo a ONU este número duplicou nas décadas seguintes. ${ }^{9}$

De 1997 em diante novo problema ganhou força no comprometimento ambiental das zonas costeiras. As mudanças climáticas, notadamente o aquecimento global, será um fator de preocupação para as regiões litorâneas. O aumento dos níveis oceânicos proviocado pelo derretimento das geleiras dos polos deve inundar uma parte considerável dos litorais, inclusive deixando muitas cidades embaixo d'água. Não obstante acreditasse que haverá, por conta das temperaturas mais elevadas, o aumento na incidência de raios e tempestades, provocando inundações, maremotos e a "ressaca" do mar deverá ser cada vez mais violenta e atingir porções maiores no interior do continente. ${ }^{10}$

Todos os problemas acima caracterizam grande parte das regiões litorâneas no mundo e no Brasil. Assim como em outras áreas, na zona costeira brasileira o processo de degradação de seus ecossistemas aumentou nos últimos anos. A urbanização acelerada, obras infraestruturais, imigração em massa e o aumento do consumo pelos habitantes e turistas agravaram a pressão sobre o meio ambiente costeiro. Exemplo dos danos

\footnotetext{
${ }^{6}$ Programa de las naciones unidas para el medio ambiente (PNUMA), Perspectivas del medio ambiente mundial. GEO-3, (Madrid: Mundi-Prensa Libros, 2002).

${ }^{7}$ Cf. Lester Brown (org.), Worldwatch Institute. Qualidade de vida-1994: salve o Planeta!, (São Paulo: Globo, 1994); Programa de las naciones unidas para el medio ambiente (PNUMA), Perspectivas del medio ambiente mundial - GEO-3, (Madrid: Mundi-Prensa Libros, 2002).

${ }^{8}$ Cf. Brown (org.), op. Cit., (1994).

${ }^{9}$ Cf. PNUMA, Op. Cit., (2002).

${ }^{10}$ Cf. International Panel on Climate Change (IPCC), Fourth assessment report: climate change, (2007).
} 
ambientais típicos do litoral brasileiro é a exploração de jazidas de areia, atividade que intensificou a erosão costeira e a conversão de áreas litorâneas para a agricultura ou aquicultura. ${ }^{11}$

No caso de São Paulo, o litoral recebeu a marca da presença humana milênios antes da colonização portuguesa. Grupos indígenas ocuparam este espaço utilizando as bases físicas e bióticas para a manutenção de sua vida social. Dinâmica mantida com a chegada e estabelecimento dos portugueses, servindo ao abastecimento colonial e a entrada de escravos que rumavam para outras regiões da América Portuguesa ou em direção ao planalto paulista. ${ }^{12}$ Em período recente o litoral paulista passou por profundas modificações paisagísticas e de urbanização. Desde 1970, sob a perspectiva do planejamento estatal, os municípios receberam obras de saneamento e estrutura visando essencialmente o turismo. ${ }^{13}$ Nesta mesma década a indústria petrolífera acomodou-se na região, com a instalação de plataformas no mar e a construção de polo petroquímico e industrial em Cubatão e São Sebastião, duas atividades que tiveram significativos impactos sociais e ambientais. ${ }^{14}$

Essas alterações urbanísticas foram acompanhadas pela constituição de áreas de proteção ambiental. Praticamente toda a faixa litorânea de São Paulo é composta por um mosaico de unidades de conservação. São unidades de diferentes tipos, sendo significativa a lista de áreas protegidas, entre elas: Parque Nacional Serra da Bocaina, Parques Estaduais Carlos Botelho, Serra do Mar, Ilha Anchieta, Ilhabela, Ilha do Cardoso, Laje de Santos, Intervales, Jacupiranga, Jurupará, Pariquera-abaixo, Alto do Ribeira e Xixová-Japuí, Estações Ecológicas Federais Tupinambás e Tupiniquins, Estações Ecológicas Estaduais Chauás, Juréia-Itatins e Xituê, Áreas de Proteção Ambiental Cananéia-Iguape-Peruíbe, Ilha Comprida e Serra do Mar, Reserva Biológica Paranapicaba, Áreas Sob Proteção Especial Juréia, Boissucanga, Costa do Navio e Centro de Biologia Marinha da Universidade de São Paulo, Áreas de Relevante Interesse Ecológico Ilha do Ameixal, Ilhas Queimada Grande e Queimada Pequena e Ilha Comprida, além da delimitação de Terras Indígenas e o tombamento de outras várias áreas naturais, como a Serra do Mar. Em 2008, o Estado de São Paulo definiu três APAs Marinhas Litoral Norte, Litoral Sul e Litoral Centro. ${ }^{15}$

A existência de áreas de conservação mostra que o litoral paulista é um espaço extremante vulnerável. Esta fragilidade é causada pelo histórico de ocupação humana e agravada pelas atividades relacionadas à exploração petrolífera. O início da extração do Présal em 2009 no campo Lula inaugurou a intensificação dos processos prejudiciais ao meio ambiente litorâneo. De forma direta são problemas ambientais potenciais os açidentes nas plataformas, oleodutos, navios-tanque, pool de combustíveis e transportes terrestres. Muitas são as possíveis causas de um vazamento de petróleo e seus derivados no ambiente litorâneo. Indiretamente, o maior risco a ser enfrentado são as mudanças climáticas.

Acidentes causados pelas atividades petrolíferas não são incomuns. Os vazamentos de grande impacto ocorridos em navios petroleiros tiveram seu primeiro registro em 1967

\footnotetext{
${ }^{11}$ Cf. Ana Maria Torres Rodrigues, "A gestão ambiental e a zona costeira: como operar nesta área complexa, onde se sobrepõem tantos usos e conflitos?", in Contrapontos, 1, (2003), 97-105; Antônia Cecília Z. Amaral; Silvio Jablonski, "Conservação da biodiversidade marinha e costeira no Brasil", in Megadiversidade, 1, (2005) 43-51; Neves; Muehe, Op. Cit., (2008); Celia Regina de Gouveia Souza, "A erosão costeira e os desafios da gestão costeira no Brasil”, in Revista da Gestão Costeira Integrada, 1, (2009)17-37.

${ }^{12}$ Cf. Caio Prado Jr. A cidade de São Paulo: geografia e história, (São Paulo: Brasiliense, 1998); Warren Dean, A ferro e fogo: a história e a devastação da Mata Atlântica brasileira, (São Paulo: Companhia das Letras, 1996); Antônio Carlos Diegues, "O Vale do Ribeira e Litoral de São Paulo: meio-ambiente, história e população" in Terra Paulista: trajetórias contemporâneas, ed. Maria Alice Setúbal, (São Paulo: CENPEC, Imprensa Oficial, 2008)

${ }^{13}$ Cf. Diegues, Op. Cit., (2008).

${ }^{14}$ Cf. José Mauro de Morais, Petróleo em águas profundas: uma história tecnológica da Petrobras na exploração offshore, (Brasília: IPEA: Petrobrás, 2013).

${ }^{15}$ Cf. Ministério do Meio Ambiente (MMA). Mata Atlântica: patrimônio nacional dos brasileiros, (Brasília: MMA, 2010).
} 
quando houve o acidente com a embarcação Torrey Canyon, com mais de 119 mil toneladas de petróleo poluindo a região costeira da Inglaterra. Nas décadas seguintes duas dezenas de acidentes no mar foram registradas, milhares de toneladas de petróleo foram despejados em oceanos, atingindo praias, baias, enseadas. Os danos à biodiversidade foram incomensuráveis. Acidente exemplar pelos danos ambientais aconteceu com o petroleiro Exxon Valdez em 1989 na região do Alaska. Apesar da pequena quantidade de óleo derramado (37 mil toneladas) o local em que se espalhou é um santuário da vida selvagem dos EUA e um famoso local de pesca. A limpeza custou mais de 2 bilhões de dólares e movimentou cerca de dez mil pessoas. ${ }^{16}$ Recentemente, em 2010, o vazamento em uma tubulação submarina no Golfo do México, na área de extração conhecida como Deepwater Horizon, contaminou toda a região com 800 mil toneladas de petróleo.

No Brasil, o histórico de vazamentos e demais acidentes na exploração e transporte de petróleo não é melhor. O primeiro registro nacional é de 1960 com a explosão do navio petroleiro Sinclair Petrolore. No litoral paulista os acidentes começaram em 1974 com o navio Takimiya Maru e em 1978 o Brazilian Marina, em ambos casos houve derramamento de seis mil toneladas de petróleo no canal de São Sebastião. O início das atividades envolvendo o Pré-sal foi marcado pelo aumento dos acidentes, vazamentos e derramamentos de óleo. Segundo informações da Folha de S. Paulo, em 2009 no Brasil foram reportados 269 casos, outros 375 em 2010, apesar da maioria referir-se aos acidentes de trabalho, estão listados também os vazamentos de petróleo, de pequena ou grande monta. ${ }^{17}$

O caso brasileiro mais recente foi a ruptura em um dos poços operados pela multinacional Chevron em novembro de 2011, no Campo do Frade localizado na Bacia de Campos/RJ. A rachadura demorou mais de vinte dias para ser parcialmente fechada, quase 600 mil litros de petróleo vazaram, uma área de mais de $163 \mathrm{~km}^{2}$ foi atingida e causou prejuízos ambientais significativos para toda a região. Depois de dois anos ainda uma pequena quantidade de óleo vazava do poço, pouco mais de quatro a cinco barris por dia. A empresa Chevron foi condenada a pagar 95 milhões de reais pelos danos causados para o meio ambiente e os pescadores, além de ter parte de suas atividades proibidas em território brasileiro. ${ }^{18}$ No litoral paulista os acidentes também são frequentes. Em 2013 uma válvula deixada aberta em um terminal da Petrobrás liberou 3.500 litros de combustível marítimo, contaminado dez praias e um manguezal em Caraguatatuba, causando danos para a maricultura e pesca na região. ${ }^{19}$ Em 2015 um vazamento de gás em polo petroquímico na cidade de Cubatão intoxicou oitenta pessoas e também prejudicou a qualidade do ar na cidade..$^{20}$

Essa diversidade de acidentes com petróleo em vários países mostram que são bem conhecidos os prejuízos ambientais pelo derramamento de óleo nas zonas costeiras. 0 petróleo atua impedindo as trocas de gases entre água e o ar, causando problemas na manutenção da diversidade marinha, como os fitoplânctons por exemplo, que não conseguem realizar a fotossíntese e suas cadeias tróficas. As aves marinhas afetadas ficam impossibilitadas de alçar voo. No solo o petróleo penetra profundamente e dificulta a

\footnotetext{
${ }^{16}$ Cf. Guy Tarade, O livro negro da poluição, (Lisboa: Bertrand, 1980)

${ }^{17}$ Cf. "Acidentes em Plataformas Crescem 40\% em um ano", Folha de S. Paulo, 29 ago., 2011

${ }^{18}$ A Chevron em 2013 assinou um Termo de Ajustamento de Conduta (TAC) neste valor, como uma forma de encerrar o processo judicial que provavelmente a faria pagar um valor muito maior em torno de 40 bilhões de reais ("Chevron faz acordo de R\$ 95 mi, 2 anos após vazamento", Folha de S. Paulo, 14. set. 14, 2013).

${ }^{19}$ Cf. "Petrobras: válvula deixada aberta causou vāzamento de óleo no litoral de São Paulo", O Globo, 14 abr., 2013.

${ }_{20}$ Cf. Bruno Merlin, "Vazamento de Gás leva 80 ao Hospital em Cubatão", Folha de S. Paulo, 24 jan., 2015.
} 
retirada de nutrientes pelas raízes das plantas e pode mesmo causar o extermínio da flora de uma região inteira. ${ }^{21}$

Os derivados do petróleo também apresentam uma ação no meio ambiente bem conhecida das ciências. Pesticidas provocam a bioacumulação de seus efeitos tóxicos em plantas e vegetais que depois são transferidas para o organismo humano e de animais. Metais pesados quando lançados sem tratamento no ambiente levam ao aparecimento de doenças degenerativas e anormalidades em fetos. Plásticos causam a mortandade de peixes e tartarugas e ao serem lançados no esgoto geram a eutrofização da água de rios e córregos. Efluentes térmicos causam mudanças profundas na biota local, como a perda de diversidade, além de estimular maior atividade química do solo. ${ }^{22}$

Para o Pré-sal todos estes tipos de danos devem ser contabilizados e devido às perfurações em grandes profundidades o comprometimento ambiental pode ser intensificado. Um dos agravantes são as obras para melhorar, ampliar ou construir a infraestrutura para a exploração do Pré-sal. Estas também terão consequências ao meio ambiente do litoral paulista. São treze os principais projetos, agrupados em três polos por especialistas em impacto ambiental: Complexo da Industria de Petróleo e Gás, Complexo Portuário de São Sebastião e Complexo Rodoviário Nova Tamoios. Ao todo, estes projetos terão investimentos de aproximadamente 53 bilhões de reais, de um total de 250 bilhões para toda a região até $2035 .^{23}$

No setor de transporte aéreo estão planejados a construção ou ampliação de aeroportos e heliportos. Tais obras são voltadas especialmente para o transbordo de pessoal entre as plataformas e o litoral. Também na chegada de materiais para a indústria petrolífera, de técnicos, investidores. Melhorias nos acessos aos aeroportos, modificação de sua finalidade, de transporte de pessoas para de cargas. As ferrovias servirão de ligação entre o litoral e o planalto do Estado. Por meio do transporte ferroviário parte da produção será enviada para a plantas petroquímicas na região da capital paulista. No caso, seria necessário ampliar a oferta de trens e de vagões de transporte de líquidos e criar uma cultura ferroviária pela utilização de trens em lugar de caminhões no transporte do petróleo e seus derivados. O transporte hidroviário deve ser ponto nodal. A grande distância a serem percorridas entre as plataformas e as cidades litorâneas, são aproximadamente $200 \mathrm{~km}$ requer a fabricação de navios para atender as diversas demandas. A Petrobrás prevê a construção de aproximadamente 595 estruturas marítimas até $2020,{ }^{24}$ sendo 250 barcos de apoio e 88 navios petroleiros. Ampliação de portos, notadamente Santos e São Sebastião, prevê o aumento do calado para receber navios de grande porte, mudanças nos planos de zoneamento portuário. Novos oleodutos irão compor também a paisagem litorânea. A construção de canais chamados de onshore e offshore pretendem a ligação rápida entre as plataformas e os tanques de armazenamento no litoral e o escoamento para as cidades do interior, onde ocorrerá o refino e a distribuição do produto. O Plano Diretor de Dutos de São Paulo deverá ser readequado para atender a demanda futura de crescimento da rede de dutos paulistas. O transporte rodoviário também receberá atenção. Uma complexa rede viária foi projetada para atender ao Pré-sal. Duplicação de rodovias, implantação de novas estradas, contornos e uma adequação legislativa (regras de transporte especial para cargas perigosas), estão em curso ou em fase de concretização. Soma-se a tudo isto a construção de estaleiros, retroportos, indústrias petroquímicas, refinarias, distribuidoras, pools de

\footnotetext{
${ }^{21}$ Cf. Brown (org.), Op. Cit., (1994); PNUMA, Op. Cit., (2002).

22 Idem.

${ }^{23}$ Cf. Teixeira et. al., Op. Cit., (2012).

24 Estruturas marítimas são consideradas três classes: 1 - navio de pequeno porte, embarcações portuárias e de patrulhamento da costa, 2 - navios de médio p̄orte e embarcações de apoio offshore e 3 - navios de grande porte, embarcações de transporte de petróleo e de cabotagem.
} 
combustíveis. Demais serviços indiretamente envolvidos nas atividades do Pré-sal, tais como a ampliação da rede hoteleira, supermercados, postos de combustíveis, comércio varejista de vestuário e eletrodomésticos e serviços em geral (mecânicas, assistências técnicas, eletricistas, pedreiros e encanadores). ${ }^{25}$

São esperados o incremento nos níveis de $\mathrm{CO}^{2}$, supressão da vegetação, acidentes ambientais, como os vazamentos, alteração na qualidade das águas superficiais, alteração no uso do solo e outros impactos de característica social como o aumento nas vagas de trabalho e da receita dos municípios afetados. A construção de infraestrutura, tanto em terra quanto em alto mar, pode causar pressão sobre os recursos naturais e os ecossistemas. Erosão, deslizamentos de terra, enchentes e inundações são fenômenos esperados por especialistas devido às modificações na paisagem provocadas por estes grandes empreendimentos. A qualidade da água deve piorar, pois as obras afetarão lençóis freáticos e rios que abastecem a região. A interação entre os ecossistemas litorâneo, serrano e costeiro pode ficar comprometida com os corredores ecológicos afetados, limitando os espaços naturais do habitat de diversas espécies. Exemplo é a Usina de Tratamento de Gás Monteiro Lobato, em Caraguatatuba e seu gasoduto de ligação com a cidade de Taubaté. A obra abrange diversos espaços e os canos invadem tanto a Planície quanto o Planalto Atlântico. Essa expansão infraestrutural atingirá invariavelmente as unidades de conservação, afetando a biodiversidade local e o potencial turístico. ${ }^{26}$

Diante destes problemas ambientais o Governo Federal e organismos internacionais apresentam uma variedade de políticas públicas, legislação e planos emergenciais. Instrumentos regulatórios que procuram prevenir ou controlar os impactos ao meio ambiente causados pela atividade petrolífera. Desde a década de 1950 está em vigor uma série de medidas nacionais e internacionais. No Brasil existem políticas públicas e programas governamentais para tentar conter a degradação ambiental e regular as atividades produtivas no litoral. O Ministério do Meio Ambiente lançou em 1997 o Plano Nacional de Gerenciamento Costeiro, ampliado em 1998 e atualizado em 2004. Em 2003 criou o Plano de Áreas para o Combate à Poluição por Óleo. Em 2004 o mesmo ministério atualizou as Áreas Prioritárias para Conservação e colocou em funcionamento o Programa Revizee para lidar com a biodiversidade do litoral brasileiro. É de 2005 a Política Nacional para os Recursos do Mar que tenta organizar a exploração marítima. No plano internacional a mais importante política está em vigência desde 1954 e foi criada pela Organização das Nações Unidas. Trata-se da Convenção Internacional para a Prevenção de Poluição do Mar por Hidrocarbonetos (OilPol), um acordo entre nações voltado para conter os possíveis danos ambientais da atividade petrolífera.

Dentre estas várias políticas nacionais existentes a mais recente veio com certo atraso. Em 2013 o Governo Federal lançou o Plano Nacional de Contingência (PNC) (Decreto $N^{\circ}$ 8.127/13) que fornece diretrizes ao vazamento de óleo no mar. Em gestação desde 2000, o PNC só foi acelerado e colocado na pauta política depois do vazamento da Chevron em 2011. Devido à falta de padronização na reposta aoș acidentes deste tipo, o Governo Federal foi pressionado a levar em frente um plano integrado de forma que houvesse uma reação imediata aos acidentes envolvendo derramamento de petróleo. A questão era evitar que o dano causado pela Chevron ocorresse novamente. O PNC determina as ações para responder aos possíveis acidentes. Define a necessidade de

\footnotetext{
${ }^{25}$ Cf. Mariana Jundirian Corá, "Pré-sal X Caraguatatuba: qual a relação?" in Revista Pensamento e Realidade, 3, (2011), 121-140; Teixeira et. al., Op. Cit., (2012); Massara et. al, Op. Cit., (2014)

${ }^{26}$ Cf. Sergio R. S. Barros et. al., "Risco ambiental na zona costeira: uma proposta interdisciplinar de gestão participativa para os Planos de Controle e Emergências dos portos brasileiros", in Revista da Gestão Costeira Integrada, 2, (2010), 217227; Corá, Op. Cit., (2011); Teixeira et. al, Op. Cit., (2012).
} 
relatórios de sensibilidade ambiental para as áreas adjacentes aos poços de petróleo ou nas rotas marítimas utilizados pelos navios de transporte do produto e de pessoal. 0 documento é amplo e prevê ações em todo o sistema hídrico nacional, não apenas no oceano Atlântico. ${ }^{27}$ Conforme estabelecido o PNC:

Fixa responsabilidades, estabelece estrutura organizacional e define diretrizes, procedimentos e ações, com o objetivo de permitir a atuação coordenada de órgãos da administração pública e entidades públicas e privadas para ampliar a capacidade de resposta em incidentes de poluição por óleo que possam afetar as águas sob jurisdição nacional, e minimizar danos ambientais e evitar prejuízos para a saúde pública. ${ }^{28}$

As políticas públicas em vigor e a legislação nacional e internacional têm como efeito fornecer resposta aos acidentes com vazamento de óleo no litoral brasileiro. Compreendendo uma série de ações fiscalizatórias, padrões de qualidade de equipamento e nível técnico a serem empregados na indústria petroleira nacional, formas de avaliar e responder aos danos causados pelos derramamentos de petróleo e seus derivados. Forma um quadro de medidas institucionais para conter os problemas ambientais diretamente causados pela atividade petrolífera. ${ }^{29}$

Tais leis e políticas não atendem aos danos indiretos que a exploração do petróleo pode causar. O acréscimo de $\mathrm{CO}^{2}$ na atmosfera tem causado, desde o início do século XX, o aumento das temperaturas médias no planeta. Aproximadamente de $1,6^{\circ} \mathrm{C}$ foi a elevação dos termômetros nos últimos cem anos. A principal causa da potencialização do efeito estufa está na queima dos combustíveis fósseis (petróleo, carvão e gás natural) por indústrias e automóveis. ${ }^{30}$ Nesse ponto, o Pré-sal tem um agravante. Estudos comprovaram que estas reservas apresentam uma concentração maior de dióxido de carbono $\left(\mathrm{CO}_{2}\right)$, em torno de $8 \%$ a $12 \%$, que os tradicionais poços petrolíferos. ${ }^{31}$

A existência desde 2007 do Plano Nacional sobre Mudanças no Clima (PNMC) não será suficiente para conter os danos provocados por essa injeção de petróleo no mercado nacional. O PNMC previa estudos de impacto climático relativos ao uso do petróleo e seus derivados. Não foi possível encontrar essas conclusões. A previsão, realizada por outros trabalhos é de um incremento na ordem de 3,1 bilhões de $\mathrm{CO}_{2}$ na atmosfera, isto somente quanto estimadas as quantidades de dióxido de carbono que serão liberados nos próximos anos pelos campos de lara e Tupi, ambos no litoral paulista. ${ }^{32}$

Os danos advindos das mudanças climáticas atingem o litoral como um todo, sua população, biodiversidade e áreas de proteção. Os dados compilados pelo Intergovernmental Panel on Climate Change (IPCC) ao longo da década de 1990 e anos 2000, publicados em relatórios e aprovados por governos, revelam a gravidade para as zonas costeiras o aumento das temperaturas nos próximos anos.

\footnotetext{
${ }^{27}$ Cf. Brasil, Decreto n. 8.127, de 22 de outubro de 2013 - Plano Nacional de Contingência de para Incidentes de Poluição por Óleo em Águas sob Jurisdição Nacional. (2013).

${ }^{28}$ Idem

${ }^{29}$ Cf. Brasil, Op. Cit., (2013); Markku Aaltonen; Elizabeth Nunes Alves, Implementação do Plano Nacional de Contingência, (Brasília: IBAMA, 2015).

${ }^{30}$ Cf. Intergovernmental Panel on Climate Changes (IPCC), First assessment report: climate change, (1995).

${ }^{31}$ Cf. Paulo César Ribeiro Lima, "O Pré-sal e o aquecimento global" in Estudo, (2009), 3-20.

${ }^{32}$ Cf. Brasil, "Decreto n. 6.263, de 21 de novembro de 2007 - Plano Nacional sobre Mudança do Clima", (2007); Paulo César Ribeiro Lima, "O Pré-sal e o aquecimento global" in Estudo, (2009), 3-20.
} 
Para os oceanos a expectativas dos cientistas climáticos em 1995 era de que ocorresse a elevação dos níveis oceânicos em torno de $40 \mathrm{~cm}$. Esse aumento geraria riscos para a biodiversidade marinha, a diminuição da produtividade e nutrientes marinhos. $\mathrm{O}$ uso humano dos oceanos seria prejudicado também com a diminuição das espécies preferenciais para a pesca, aumento na quantidade de furacões e tornados, embraquecimento de recifes de corais. Especificamente para as zonas costeiras o IPCC indica que devido ao alto grau de exploração destas regiões sua capacidade de suportar as alterações climáticas é pequena. O aumento dos níveis oceânicos será um risco significativo para as populações dessas regiões. Nos dados fornecidos pelo relatório de 2014 do IPCC os efeitos nas zonas costeiras seriam a "Submergence, flood damage, erosion; saltwater intrusion; rising water tables/impeded drainage; wetland loss (and change)". " Para o IPCC a confiabilidade destes problemas ocorrerem é alta. Os estudos apontam o aumento dos níveis oceânicos. Entre 1900 e 2014 a elevação se manteve na taxa de 1,7 mm/ano para os primeiros noventa anos e duplicou no período 1993-2010 pará $3.2 \mathrm{~mm} / \mathrm{ano}$. As causas dessa elevação devem-se em grande parte ao aquecimento dos mares e ao derretimento de geleiras nos polos. ${ }^{34}$

Para o litoral paulista estudos nacionais revelam um alto grau de vulnerabilidade às mudanças climáticas. A urbanização acentuada e sua característica geomorfológica são elementos negativos nesta situação. Para o geógrafo Omar Bitar as particularidades do litoral paulista abrem possibilidade para que as mudanças climáticas ampliem problemas ambientais existentes. A região apresenta uma geodinâmica que naturalmente leva a deslocamentos de solo, que por sua vez provocam "erosão, escorregamento, expansão do solo, afundamento cárstico, inundação, colapso do solo ou dinâmica costeira". "Neste cenário a infraestrutura e a exploração do Pré-sal é um fator de agravo da situação de risco da região. A concentração das atividades do Pré-sal e a possibilidade de elevação do nível oceânico, tempestades, tornados, aumento na sedimentação, pode aumentar os riscos de vazamentos, explosões, gerando, por fim, inviabilidade econômica na exploração de petróleo. ${ }^{36}$

Eventos extremos ocorreram na Baixada Santista em passado recente. No ano de 1967 na cidade de Caraguatatuba, onde hoje é o Parque Estadual Serra do Mar, uma tempestade de grandes proporções levou ao deslizamento de terra e morte de quatrocentas pessoas. Alargou o canal do Rio Santo Antônio em mais de cinquenta metros, carregando arvores e troncos, e destruindo a infraestrutura urbana da cidade. Em 1996 um verão fora dos padrões afetou o regime de chuvas, levando a inundações, deslizamentos e o fechamento da rodovia dos Tamoios. ${ }^{37}$ Apesar de não estarem relacionados com as mudanças climáticas estes eventos fornecem indícios necessários para entender a situação que a região do litoral paulista terá de enfrentar devido ao aquecimento global.

A bibliografia especializada em gestão costeira no Brasil informa que, até 2010 pelo menos, o país, mesmo com o Plano Nacional sobre Mudanças no Clima em vigor, não tem um conjunto de ações definidas para atenuar os impactos do aquecimento global na zona costeira. Os impactos ambientais podem ser agravados ainda mais com as mudanças

\footnotetext{
${ }^{33}$ Cf. International Panel on Climate Changes, Fifth assessment report: climate change, (2014), 368.

34 Idem.

${ }^{35}$ Cf. Omar Yazbek Bitar, "Infraestrutura, meio físico e mudanças climáticas: novos desafios ao litoral do Estado de São Paulo", in IF Sér. Reg., 40, (2009), 12.

${ }^{36}$ Cf. Bitar, Op. Cit., (2009); João Luiz Nicolodi; Rafael Mueller Petermann, "Mudanças climáticas e a vulnerabilidade da zona costeira do Brasil: aspectos ambientais, sociais e tecnológicos", in Revista da Gestão Costeira Integrada, 2, (2010), 151-177.

${ }^{37}$ Cf. Luciana M. F. Braga Castro et. al., "Mudança climática, riscos e vulnerabilidade: um estudo dos eventos ocorridos em 1967 e 1996 na planície litorânea de Caraguatātuba/SP", in CLIMEP - Climatologia e Estudos da Paisagem, 1-2, (2011), 22-43.
} 
sociais que estão ocorrendo na região devido as atividades do Pré-sal. Os grandes investimentos previstos para os próximos anos e o comprometimento ambiental pela exploração petrolífera invariavelmente vão levar a intensificação dos efeitos climáticos sobre o litoral paulista. ${ }^{38}$

\section{Mudanças sociais e cidadania}

A atividade de extração petrolífera acarreta a modificação da paisagem social nas regiões que se estabelece. Grande contingente imigratório, crescimento demográfico, aumento da pobreza, déficit de habitações, epidemias, insuficiência de escolas, creches e centros educacionais, malha viária urbana superada, perda da diversidade econômica. Todos são elementos encontrados nas alterações do cenário urbano no entorno da exploração de petróleo.

Os processos envolvendo a cadeia produtiva do petróleo são historicamente associados à imigração de grandes contingentes de trabalhadores. A mão-de-obra necessária para lidar com as tarefas direta e indiretamente relacionadas à atividade petrolífera não é atendida pela população autóctone das regiões onde estão localizados os campos, atraindo trabalhadores de outras partes do país ou mesmo do estrangeiro. ${ }^{39}$

O crescimento da imigração em direção às cidades litorâneas de São Paulo é um fenômeno que vem ocorrendo desde 2007. Os municípios desta região têm apresentado aumento na oferta de postos de trabalho. Grande parte são empregos temporários, relativos à instalação da infraestrutura e logística do Pré-sal. O consequente incremento na economia local poderia ocasionar a permanência dos imigrantes. No litoral paulista a estimativa é de crescimento demográfico acima de $28 \%$ para os próximos anos. Somente na cidade de Caraguatatuba a população aumentou 29,9\% entre 2000 e 201140.

A atração dos novos postos de trabalho transforma essas cidades em eldorados modernos. O aumento do emprego é perceptível pelos índices levantados entre 2008 e 2010 pela Comissão Especial de Petróleo e Gás do Estado de São Paulo (CESPEG). A Baixada Santista foi responsável pelo aumento, na última década, de 38,8\% nos postos de trabalho formal no estado, ficando atrás apenas de cidades maiores (como São Paulo e Campinas). Quando comparado este número com a década anterior (anos.1990), a evolução é significativa, a região teria sido responsável por apenàs $2,86 \%$ dos trabalhadores do Estado. ${ }^{41}$ Segundo informações divulgadas pela revista Carta Capital apenas na cidade de Santos o PIB per capita era, em 2012, de 54 mil reais, a renda média de 3,3 salários e as principais vagas de emprego ofertadas eram de vendedores, servente de obras e engenheiros. Empregos que em sua maioria são direcionados a infraestrutura do Pré-sal. Dados que demonstram a atratividade do litoral paulista para os trabalhadores de outras partes do estado e do país. ${ }^{42}$

O aumento demográfico somado à oferta de empregos movimenta também a construção de habitações e, consequentemente, a aceleração na ocupação do solo. Todas

\footnotetext{
${ }^{38}$ Cf. Neves; Muehe, Op. Cit., (2008); Bitar, Op. Cit., (2009); Sonia Regina da Cal Seixas et. al., "Mudanças ambientäis globais, vulnerabilidade e risco: impactos na subjetividade em Caraguatatuba, Litoral Norte Paulista", in Revista Vitas Visões Transdisciplinares sobre Ambiente e Sociedade, 1, (2011), 1-28.

${ }^{39}$ Cf. Santiago, Op. Cit., (2006)

${ }^{40}$ Cf. Corá, Op. Cit., (2011).

${ }^{41}$ Cf. São Paulo (Estado); Comissão Especial de Petróleo e Gás Natural, "Relatório Final de Atividades - Levantamentos, análises estratégicas e recomendações propostas pelos nove grupos de trabalho da Cespeg entre 2008 e 2010 ", (CESPEG, São Paulo, 2010).

${ }^{42}$ Cf. Cintra, Op. Cit., Jul. 11, 2012
} 
as cidades da Baixada Santista estão polvilhadas de canteiros de obras. Prédios de apartamentos, residências baixas, condomínios fechados estão em construção ou já formam a paisagem urbana e visam abrigar os fluxos populacionais crescentes. Grande parte de destes empreendimentos, no entanto, são de moradias luxuosas, para atender um público especifico e que não habitam as cidades litorâneas. ${ }^{43}$

A nova realidade destes municípios, aparentemente, seria de um desenvolvimento econômico e social acentuado. A atratividade de empregos, o aumento populacional, a renda dos royalties e dos investimentos em logística e infraestrutura petrolífera seriam elementos de impacto social positivo em toda a região. A realidade social, contudo, não pode ser vista apenas a partir desses aspectos.

No estudo divulgado em 2011 pela Secretaria de Planejamento e Desenvolvimento Regional a Baixada Santista teve entre 1980 e 2010 um crescimento demográfico superior às taxas estaduais. Os municípios da região apresentaram índices de urbanização de $98,9 \%$, quando a média estadual para o mesmo período foi de 95,9\%. No relatório a Baixada Santista era considerada uma região rica, porém, com condições sociais abaixo da média. Os principais problemas levantados pelo relatório foram: baixa escolaridade, saúde precária, pouca longevidade da população e altas taxas de mortalidade infantil. Elementos que justificam a imigração como principal fator de crescimento demográfico da região e não o aumento da população nativa. ${ }^{44}$ Os dados, quando consolidados com o aumento do emprego na região, revelam que o litoral paulista deve ser compreendido como uma região de urbanização acentuada, com altos índices de pobreza e de tendência ao inchaço demográfico.

Junto do crescimento populacional no litoral o colapso dos sistemas de saúde, saneamento, escolar, segurança pública, cultural, viário são também uma realidade. Investimentos precários ou sem objetividade, corrupção e desvios de verbas, falta de projetos políticos, levam os royalties do petróleo a serem pulverizados, sem que suas finalidades sejam atingidas.

Um cenário de agravamento da situação é esperado, especialmente no caso da saúde ambiental. Os problemas de saúde gerados pelas atividades petrolíferas são bem conhecidos da medicina contemporânea. No caso do Pré-sal, a singularidade do tipo de exploração - em alto mar e grande profundidade - seus riscos específicos à saúde não seriam conhecidos. Alguns pesquisadores, como Helena Ribeiro da USP, fizeram levantamentos sobre os possíveis riscos para populações litorâneas. São três categorias principais: riscos químicos, psicossociais e físicos. Entre os químicos, os problemas maiores seriam referentes a intoxicação humana, devido a vazamentos de petróleo e seus derivados. Na categoria psicossocial destaca-se o stress e para os riscos físicos os ruídos e acidentes de trabalho. ${ }^{45}$

Relacionados a estes problemas, apontados por Helena Ribeiro, existe uma série de fatores que podem acentuar os danos para a saúde das populações litorâneas. O colapso dos equipamentos urbanos de atendimento aos habitantes das cidades pode ser uma questão iminente. Na comparação com as cidades do litoral carioca é possível dimensionar esse problema. Estudos de 2010 mostram que nos municípios da Bacia de Campos apesar do grande retorno financeiro dos royalties do petróleo (sendo esta a principal região de exploração de petróleo antes do anúncio do Pré-sal) seus habitantes não apresentaram uma

\footnotetext{
${ }^{43}$ Cf. "Pobres cidades ricas", in UNESP Ciência, 5, (2011), 24-31

${ }^{44}$ Cf. São Paulo (Estado); Secretaria de Planejamento e Desenvolvimento Regional, "Caracterização socioeconômica de São Paulo - Região metropolitana da Baixada Santista", (SPDR, 2011).

${ }^{45}$ Cf. Helena Ribeiro, "Impactos da exploração do petróleo na saúde humana", in Revista USP, 95, (2012); 61-71.
} 
melhora nas condições de vida. Ao contrário, mesmo com o aumento de investimento público em saúde, educação, moradia, segurança, tal como previsto no uso dos royalties, os moradores em situação de risco social não puderam aproveitar os benefícios. Em todas essas áreas a falta de planejamento, irregularidades nos financiamentos, superfaturamentos, desvios de verbas e corrupção foram identificados como os motivos que levaram ao aumento da distância entre os royalties e sua finalidade: a compensação das desigualdades sociais. ${ }^{46}$

A pressão imobiliária na ocupação do solo no litoral paulista é outro problema. A região apresenta um histórico de ocupação irregular por empreendimentos turísticos e casas de veraneio. ${ }^{47}$ Ao receber anualmente milhares de turistas, provenientes da capital e outras cidades do interior paulista e do país, a pressão imobiliária empurrava para fora dos espaços ideais de habitação a população carente. A Fundação SEADE identificou em 2006 que na Região Metropolitana da Baixada Santista existia um déficit de $72 \%$ em habitações e a inadequação de moradias estaria em torno de $73 \%{ }^{48}$ Uma situação que tem a llha de São Vicente como seu centro dispersor, conforme os dados da Secretaria de Planejamento e Desenvolvimento Regional, em 2011:

O espraiamento urbano da região, da llha de São Vicente, sobretudo em direção ao sul, teve como consequência não só o crescimento demográfico das áreas periféricas, mas, também a concentração de população de mais baixa renda em áreas cada vez mais distantes do centro regional, ou em áreas menos valorizadas, em função de sua localização, dos municípios mais centrais como Guarujá, Cubatão ou São Vicente, na parte continental. Nesse caso, esse estrato populacional acabou por se localizar em áreas lindeiras às estradas, próximas aos vales dos rios e manguezais ou no sopé da Serra do Mar. ${ }^{49}$

A população carente ao fixar-se nestas áreas acentua o problema urbano no litoral paulista. Dois tipos de conflitos ficam caracterizados. O primeiro, ambiental, causado pelas moradias em regiões de risco (enchentes, deslizamentos de encostas) que podem ser intensificadas e maior frequência de ocorrer devido aos efeitos do aquecimento global nos próximos anos. Ainda conforme os dados de 2011 da Secretaria de Habitação do Estado de São Paulo, 78\% das ocorrências registradas no Estado por conta de habitação em áreas de risco foram na Baixada Santista. ${ }^{50}$ Deve-se apontar também a invasão de áreas de proteção ambiental, existentes em cidades como Caraguatatuba onde entre 20\% e 25\% das áreas de proteção ambiental, desde áreas sob legislação federal até as municipais, apresentam algum tipo de ocupação irregular. ${ }^{51}$

O segundo conflito é de ordem social e aparece quando observada a modificação urbana causada pelos investimentos do Pré-sal. Mesmo com o pouco tempo entre a descoberta e o início das atividades houve a modificação das paisagens urbanas. A especulação imobiliária tem empurrado cada vez mais a população menos favorecida para

\footnotetext{
${ }^{46}$ Cf. "Pobres cidades...", Op. Cit., (2011).

${ }^{47}$ Cf. Michelle Renk, "Percepção de riscos no setor energético: um estudo de caso envolvendo o gasoduto de Mexilhão/Petrobrás em Caraguatatuba - Litoral Norte de São Paulo", (master's thesis, Universidade de Campinas, 2010).

${ }^{48}$ Cf. São Paulo (Estado); Fundação Sistema Estadual de Análise de Dados (SEADE), "Pesquisa de condições de vida", (2006).

${ }^{49}$ Cf. São Paulo (Estado); Secretaria de Planejamento e Desenvolvimento Regional, Op. Cit., (2011), 56.

${ }^{50}$ Idem.

${ }^{51}$ Cf. Mariana Jundirian Corá, "Impactos do Pré-s̄al no uso e ocupação do solo de Caraguatatuba, SP", (master's thesis, Universidade de São Paulo, 2013).
} 
fora dos espaços adequados de moradia. Esta prática aumenta o valor da terra e promove a construção de casas e apartamento de alto padrão, fatores que impossibilitam o assentamento da população pobre.

O conflito social e ambiental alcança as comunidades caiçaras e indígenas. O problema é antigo, desde 1950, com a abertura da estrada Rio-Santos (BR 101), a chegada da Petrobras e o início da indústria do turismo, essas comunidades têm sofrido a pressão territorial e cultural. Ambas arcavam com os prejuízos causados pela alta incidência de turistas, o que levava a terem seus territórios diminuídos, cercados ou mesmo invadidos por empreendimentos turísticos, agora também devem lidar com a especulação imobiliária do Pré-sal. Resorts ou condomínios fechados pretendem ocupar as áreas das comunidades que comumente são caracterizadas pela biodiversidade da Mata Atlântica. ${ }^{52}$

Os royalties do Pré-sal apesar de voltados para garantir a amenização da desigualdade social, não devem ser utilizados para dar segurança habitacional a estas populações. Mesmo porque as levas de imigrantes do Pré-sal em direção ao litoral paulista necessitarão que maiores investimentos do orçamento público sejam utilizados para suprir minimamente suas carências. Por outro lado, o dinheiro do Pré-sal irá continuar atraindo investidores e especuladores imobiliários, na construção de grandes obras e residenciais para um público restrito.

Até 2018, quando entra em operação o Campo de Libra, um dos maiores do Pré-sal, as mudanças sociais e ambientais na região da Baixada Santista podem fazem que o ouro negro seja derramado sobre a população menos favorecida. O desenvolvimento econômico e social tendo o Pré-sal como base pode ser desolador para a maioria da população brasileira, especialmente no litoral paulista.

\section{Conclusão}

O anúncio das jazidas do Pré-sal em 2007 trouxe boas expectativas para o mercado internacional de energia. Perspectivas muito mais relacionadas às possibilidades de novos ganhos pela indústria petrolífera do que pela entrada de novas reservas do produto. De fato, as jazidas do Pré-sal apenas somaram-se à conjuntura de ampliação das áreas de exploração. As reservas brasileiras entram na conta do balanço energético mundial. Somam-se às jazidas descobertas em outras regiões, como a areia pesada do Canadá, os campos petrolíferos do México, Sudão, Rússia e no Mar Cáspio. A apropriação de novas áreas extratoras reflete diretamente no aumento da produção de petróleo. A OPEP apresentou aumento de suas atividades para o período entre 2007-2014. ${ }^{53}$ A produção não acompanhou a demanda. Cada ano uma quantidade maior de energia é requerida para a manutenção dos sistemas econômicos e da sociedade. Entre 2003 e 2007 a extração cresceu $1,4 \%$ enquanto a demanda $1,9 \% .{ }^{54}$ As estimativas da OPEP apontam que entre 2010 e 2040 a necessidade de energia no planeta passará de 256,4 milhões de barris para 410,2 milhões por dia, um crescimento de 60\%. Para o petróleo, a organização indica uma taxa menor de utilização para os próxịmos anos, mas ainda assim crescente, passando de 90 milhões de barris para 111 milhões/dia até 2019. ${ }^{55}$

\footnotetext{
52 Cf. André Fida; Fábio Ricci, "Litoral Norte Paulista: a exclusão do caiçara no século XX", in Anais do XIX Encontro Regional de História: poder, violência e exclusão, (ANPUH/SP. São Paulo, 2008).

${ }^{53}$ Cf. Organization of the Petroleum Exporting Countries (OPEC), World oil outlook, (Viena: Austria, 2008); Organization of the Petroleum Exporting Countries (OPEC), World oil outlook, (Viena: Austria, 2014).

${ }^{54}$ Cf. OPEC, Op. Cit., (2008).

${ }^{55}$ Cf. OPEC, Op. Cit., (2014).
} 
No caso do Pré-sal brasileiro seu papel no mercado energético é limitado, assim como seu cacife político e econômico. Após o anúncio da descoberta em 2007 jornalistas e especialistas em relações internacionais acreditavam que as reservas do Pré-sal poderiam alavancar o Brasil na geopolítica do petróleo, até mesmo ser incluído no rol dos países membros da OPEP. O desenrolar do jogo nos anos seguintes diminuiu o valor do Pré-sal brasileiro. Os EUA, principal consumidor internacional de petróleo, vem desde 2003 explorando novas jazidas em seu território, o que poderia em longo prazo reduzir sua dependência do mercado. Soma-se a este cenário, a exploração das outras áreas mencionadas acima. Estas reservas economicamente inviáveis tornaram-se vantajosas pelos altos preços do petróleo praticados em 2015.

Apesar do anúncio do Pré-sal ter sido combinado com uma euforia política que previa a inserção brasileira na geopolítica energética mundial, a realidade imposta nos anos subsequentes foi outra. O petróleo brasileiro acabou condicionado pela indústria internacional que avançou sobre áreas antes inviáveis comercialmente e possivelmente pelos preços que tornarão proibitivos a exploração em grandes profundidades. O Pré-sal deve ter para os próximos anos um valor estratégico em território nacional, como propulsor do desenvolvimento econômico e social. Possivelmente, sua área de influência permitirá apenas que o Brasil consolide seus interesses econômicos no Atlântico Sul e junto com os vizinhos latino-americanos pode vir a representar um importante papel no mercado futuro.

A questão não diz respeito à capacidade do Brasil em explorar as jazidas do Pré-sal. Isto é demonstrado pela experiência da Petrobrás na extração em alto mar desde a década de 1970. A questão é a forma que o país irá lidar com os custos ambientais e sociais que esta atividade de extração intensa acarretarão nas regiões costeiras onde estão localizadas. O comprometimento dos ecossistemas, da biodiversidade e às mudanças climáticas é evidente. Evidente também é o espectro negativo que deixará na paisagem urbana do litoral. As políticas públicas direcionadas a estes problemas ou são deixadas de lado, como no caso da política nacional das mudanças climáticas, oú então, não existem. O papel econômico e geopolítico do Pré-sal está em primeiro plano desde 2007, já as externalidades ambientais e sociais e as perspectivas de sustentabilidade não têm sido discutidas efetivamente no debate público. 